\title{
Thyroid Hormone and Tissue Repair: New Tricks for an Old Hormone?
}

\author{
Iordanis Mourouzis, Efstathia Politi, and Constantinos Pantos \\ Department of Pharmacology, University of Athens, 75 Mikras Asias Avenue, Goudi, 11527 Athens, Greece \\ Correspondence should be addressed to Constantinos Pantos; cpantos@med.uoa.gr
}

Received 1 November 2012; Accepted 26 January 2013

Academic Editor: Giorgio Iervasi

Copyright (C) 2013 Iordanis Mourouzis et al. This is an open access article distributed under the Creative Commons Attribution License, which permits unrestricted use, distribution, and reproduction in any medium, provided the original work is properly cited.

\begin{abstract}
Although the role of thyroid hormone during embryonic development has long been recognized, its role later in adult life remains largely unknown. However, several lines of evidence show that thyroid hormone is crucial to the response to stress and to poststress recovery and repair. Along this line, $\mathrm{TH}$ administration in almost every tissue resulted in tissue repair after various injuries including ischemia, chemical insults, induction of inflammation, or exposure to radiation. This novel action may be of therapeutic relevance, and thyroid hormone may constitute a paradigm for pharmacologic-induced tissue repair/regeneration.
\end{abstract}

\section{Introduction}

Although the role of thyroid hormone (TH) during development has long been recognized, its role later in adult life remains largely unknown [1]. A growing body of evidence reveals that thyroid hormone may be a major player for the response to stress and its presence crucial to poststress adaptation and recovery. Thus, thyroid hormone is now thought to have a reparative action later in adult life, and this has been recently documented in several studies; see Table 1 .

\section{Adaptation to Environmental Stress and Species Evolution: The Critical Role of Thyroid Hormone}

The most important challenge that living organisms faced during species evolution was the ability to adapt to the transition from the aquatic environment, a condition of low oxygen, to the ground, an oxygen-rich state. This required a gene programming that would enable organ protection and remodeling during this transition. Interestingly, studies on amphibians revealed that thyroid-hormone-regulated gene programming is critical for the metamorphosis of tadpoles into juvenile frogs [2]. Several studies have shown that the morphological and functional changes of metamorphosis are the result of alterations in the transcription of specific sets of genes induced by $\mathrm{TH}$ and $\mathrm{TH}$ alterations can lead to developmental failures [3-6].

\section{Thyroid Hormone and Stress Response: An Evolutionary Conserved Mechanism}

The potential role of thyroid hormone in stress response has been, until now, underestimated. However, thyroid hormone signaling is altered during various stressful stimuli and thyroid hormone is crucial to poststress recovery and injury repair [7-9]. Interestingly, the importance of thyroid hormone for stress response has been documented in several species ranging from fish to humans [10]. Thus, exposure of air-breathing perch to water-born kerosene resulted in low T3 and unfavorable metabolic changes, while the administration of $\mathrm{TH}$ reversed this response [11]. Along this line, cold stunning Kemp's ridley sea turtles had undetectable levels of thyroid hormone, and recovery was observed only in those who recovered thyroid hormone levels in blood [12]. Interestingly, a similar response is also observed in humans. In fact, after an index event, such as myocardial infarction, T3 levels significantly drop and lower levels of T3 are associated with high mortality $[13,14]$. Furthermore, T3 levels are strongly correlated to early and late recovery of cardiac function, with T3 levels at 6 months to be an independent predictor of the recovery of the myocardium [15]. In fact, patients 


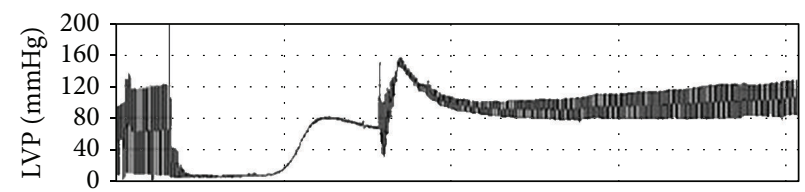

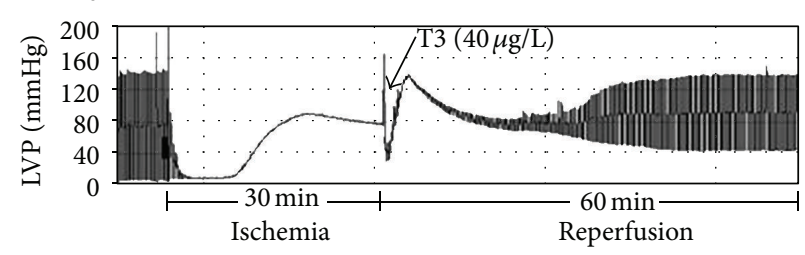

(a)

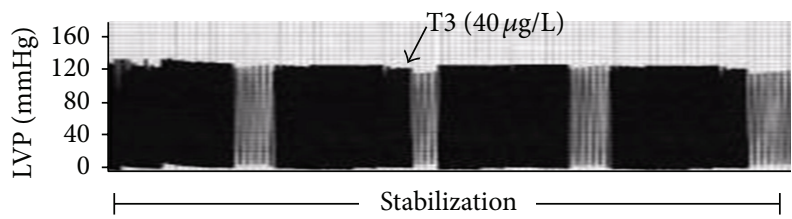

(b)

FIGURE 1: Langendorff recordings of left ventricular pressure (LVP) from isolated rat hearts subjected to zero-flow global ischemia followed by reperfusion (a) and hearts subjected only to stabilization (b). Triiodothyronine (T3) administration at reperfusion improves postischemic recovery of function, whereas T3 during stabilization does not affect contractile function.

who spontaneously recover T3 levels in plasma after myocardial infarction are those with markedly improved cardiac functional recovery [15]. These observations provide clear evidence that thyroid-hormone-regulated mechanisms may be evolutionary conserved and are crucial to the response to stress and poststress recovery and tissue repair [11]. Along this line, several studies have demonstrated the reparative action of thyroid hormone. We have recently shown that T3 at a dose which had no effect on noninjured myocardium significantly limited apoptosis in the ischemic myocardium and improved postischemic function in an isolated rat heart model of ischemia-reperfusion. This effect was due to the suppression of the ischemia-reperfusion-induced activation of the proapoptotic p38 MAPK $[16,17]$ as shown in, Figure 1.

\section{Thyroid Hormone: The "Black Box of Repair?"}

Accumulating experimental evidence shows that thyroid hormone may play a critical role in the repair after injury in almost every tissue and organ as shown in Table 1. This probably implies that organisms may have a common mechanism of repair which may be regulated by thyroid hormone and has been established during evolution. Thus, thyroid hormone was shown to control DNA repair after irradiation-induced damage in mouse intestine [38]. A single dose of T3 in rats significantly diminished hepatocellular injury induced by ischemia-reperfusion (I/R) when given $48 \mathrm{~h}$ before the I/R protocol. This effect was mediated by a T3 transient oxidative stress, and thus, it was abrogated by the administration of antioxidant $\mathrm{N}$-acetyl-cysteine [23]. Thyroxine was cytoprotective in toxic and ischemic injury in kidney $[24,26]$. Thus, T3 administration $24 \mathrm{~h}$ prior to renal ischemia could precondition against ischemia-reperfusion (I/R) injury. This was evident by a marked decrease in I/Rinduced proteinuria. T3 treatment also improved lipid peroxidation biomarkers and increased antioxidant enzymes [24]. In another study, T4 administration immediately or $24 \mathrm{~h}$ after ischemia resulted in higher Inulin clearance and preserved cellular integrity [26]. In accordance with these observations in animal models, T4 was shown to be cytoprotective, in a cellular model of reoxygenation injury in isolated proximal tubule cells [25]. Such evidence may provide an explanation to the clinical observation that low T3 has been associated with increased mortality in hemodialyzed patients [39]. T3 treatment prevented streptozocin-induced toxic injury in pancreatic cells. This effect was associated with an increased activation of the prosurvival Akt signaling [27]. Similarly, T3 was shown to improve function and survival of rat pancreatic islets in in vitro cell cultures [40]. Moreover, T3 was found to preserve ovarian granulose cells exposed to paclitaxel. In fact, T3 significantly reduced the paclitaxel-induced cell injury via downregulation of caspase 3 and Bax and upregulation of $\mathrm{Bcl} 2$ [28]. T3 pretreatment in rats instilled with an isosmolar $5 \%$ albumin solution resulted in the upregulation of alveolar epithelial fluid clearance [41]. T3 was also shown not only to stimulate alveolar fluid clearance in normal but also in hypoxia-injured lungs [29]. The administration of T3 attenuated neointimal formation after balloon injury of carotid artery [35]. Thyroid hormone enhanced transected axonal regeneration and muscle reinnervation following rat sciatic nerve injury [22] and improved recovery of sensory function [21]. Similarly, thyroid hormone was shown to be essential for muscle regeneration after injury $[33,34]$. Thyroid hormone promoted the survival of injured neurons [18] and enhanced remyelination in demyelinating inflammatory disease [20]. Thyroid hormone has also been shown to accelerate wound healing in mice and guinea pigs $[36,37]$.

\section{Conclusions}

Thyroid hormone appears to be a common player for the organ development and response to stress. Thyroid hormone was crucial for species evolution, and thyroid-hormoneregulated mechanisms have been evolutionary conserved and play an important role early during development. However, recent research has revealed that thyroid hormone has a reparative role later in adult life. This novel action may be of therapeutic relevance, and thyroid hormone may constitute a paradigm for pharmacologic induced tissue repair/regeneration. 


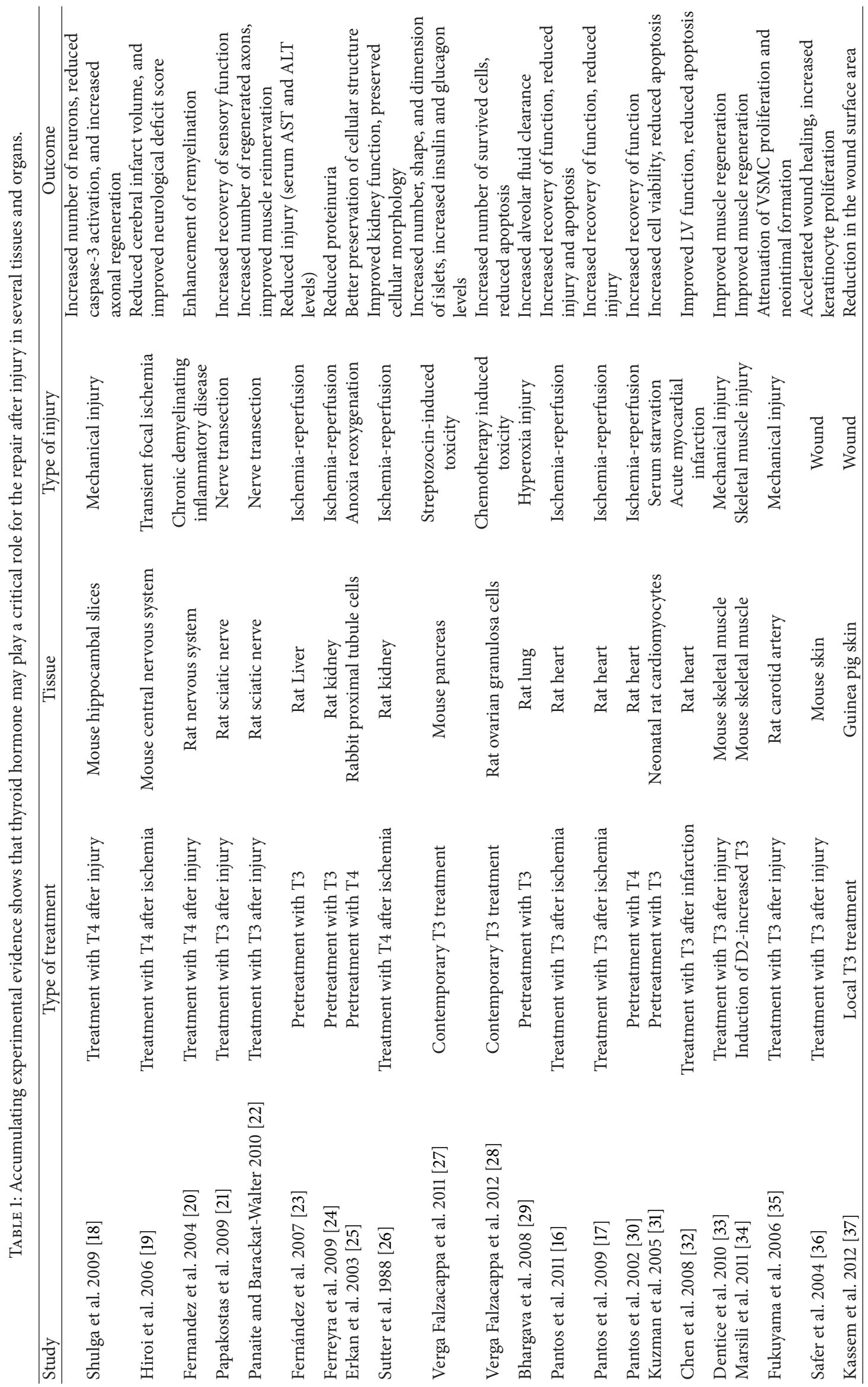




\section{References}

[1] C. Pantos, I. Mourouzis, and D. V. Cokkinos, "Thyroid hormone and cardiac repair/regeneration: from Prometheus myth to reality?" Canadian Journal of Physiology and Pharmacology, vol. 90, no. 8, pp. 977-987, 2012.

[2] J. F. Gudernatsch, "Feeding Experiments on tadpoles - I. The influence of specific organs given as food on growth and differentiation. A contribution to the knowledge of organs with internal secretion," Archiv für Entwicklungsmechanik der Organismen, vol. 35, no. 3, pp. 457-483, 1912.

[3] D. L. Berry, C. S. Rose, B. F. Remo, and D. D. Brown, "The expression pattern of thyroid hormone response genes in remodeling tadpole tissues defines distinct growth and resorption gene expression programs," Developmental Biology, vol. 203, no. 1, pp. 24-35, 1998.

[4] J. D. Furlow and E. S. Neff, "A developmental switch induced by thyroid hormone: xenopus laevis metamorphosis," Trends in Endocrinology and Metabolism, vol. 17, no. 2, pp. 40-47, 2006.

[5] J. D. Furlow, H. Y. Yang, M. Hsu et al., "Induction of Larval tissue resorption in Xenopus laevis tadpoles by the thyroid hormone receptor agonist GC-1," The Journal of Biological Chemistry, vol. 279, no. 25, pp. 26555-26562, 2004.

[6] Y. B. Shi, L. Fu, S. C. V. Hsia, A. Tomita, and D. Buchholz, "Thyroid hormone regulation of apoptotic tissue remodeling during anuran metamorphosis," Cell Research, vol. 11, no. 4, pp. 245-252, 2001.

[7] C. Pantos, I. Mourouzis, and D. V. Cokkinos, "New insights into the role of thyroid hormone in cardiac remodeling: time to reconsider?" Heart Failure Reviews, vol. 16, no. 1, pp. 79-96, 2011.

[8] C. Pantos, I. Mourouzis, and D. V. Cokkinos, "Rebuilding the post-infarcted myocardium by activating "physiologic" hypertrophic signaling pathways: the thyroid hormone paradigm," Heart Failure Reviews, vol. 15, no. 2, pp. 143-154, 2010.

[9] C. Pantos, I. Mourouzis, G. Galanopoulos et al., "Thyroid hormone receptor 1 downregulation in postischemic heart failure progression: the potential role of tissue hypothyroidism," Hormone and Metabolic Research, vol. 42, no. 10, pp. 718-724, 2010.

[10] V. S. Peter and M. C. Peter, "The interruption of thyroid and interrenal and the inter-hormonal interference in fish: does it promote physiologic adaptation or maladaptation?" General and Comparative Endocrinology, vol. 174, no. 3, pp. 249-258, 2012.

[11] V. S. Peter, E. K. Joshua, S. E. Wendelaar Bonga, and M. C. S. Peter, "Metabolic and thyroidal response in air-breathing perch (Anabas testudineus) to water-borne kerosene," General and Comparative Endocrinology, vol. 152, no. 2-3, pp. 198-205, 2007.

[12] K. E. Hunt, C. Innis, and R. M. Rolland, "Corticosterone and thyroxine in cold-stunned Kemp's ridley sea turtles (Lepidochelys kempii)," Journal of Zoo and Wildlife Medicine, vol. 43, no. 3, pp. 479-493, 2012.

[13] B. Eber, M. Schumacher, W. Langsteger et al., "Changes in thyroid hormone parameters after acute myocardial infarction," Cardiology, vol. 86, no. 2, pp. 152-156, 1995.

[14] L. Friberg, S. Werner, G. Eggertsen, and S. Ahnve, "Rapid downregulation of thyroid hormones in acute myocardial infarction: is it cardioprotective in patients with angina?" Archives of Internal Medicine, vol. 162, no. 12, pp. 1388-1394, 2002.
[15] I. Lymvaios, I. Mourouzis, D. V. Cokkinos, M. A. Dimopoulos, S. T. Toumanidis, and C. Pantos, "Thyroid hormone and recovery of cardiac function in patients with acute myocardial infarction: a strong association?" European Journal of Endocrinology, vol. 165, no. 1, pp. 107-114, 2011.

[16] C. Pantos, I. Mourouzis, T. Saranteas et al., "Acute T3 treatment protects the heart against ischemia-reperfusion injury via TR $\alpha 1$ receptor," Molecular and Cellular Biochemistry, vol. 353, no. 1-2, pp. 235-241, 2011.

[17] C. Pantos, I. Mourouzis, T. Saranteas et al., “Thyroid hormone improves postischaemic recovery of function while limiting apoptosis: a new therapeutic approach to support hemodynamics in the setting of ischaemia-reperfusion?" Basic Research in Cardiology, vol. 104, no. 1, pp. 69-77, 2009.

[18] A. Shulga, A. Blaesse, K. Kysenius et al., "Thyroxin regulates BDNF expression to promote survival of injured neurons," Molecular and Cellular Neuroscience, vol. 42, no. 4, pp. 408-418, 2009.

[19] Y. Hiroi, H. H. Kim, H. Ying et al., "Rapid nongenomic actions of thyroid hormone," Proceedings of the National Academy of Sciences of the United States of America, vol. 103, no. 38, pp. 14104-14109, 2006.

[20] M. Fernandez, A. Giuliani, S. Pirondi et al., "Thyroid hormone administration enhances remyelination in chronic demyelinating inflammatory disease," Proceedings of the National Academy of Sciences of the United States of America, vol. 101, no. 46, pp. 16363-16368, 2004.

[21] I. Papakostas, I. Mourouzis, K. Mourouzis, G. Macheras, E. Boviatsis, and C. Pantos, "Functional effects of local thyroid hormone administration after sciatic nerve injury in rats," Microsurgery, vol. 29, no. 1, pp. 35-41, 2009.

[22] P. A. Panaite and I. Barakat-Walter, "Thyroid hormone enhances transected axonal regeneration and muscle reinnervation following rat sciatic nerve injury," Journal of Neuroscience Research, vol. 88, no. 8, pp. 1751-1763, 2010.

[23] V. Fernández, I. Castillo, G. Tapia et al., “Thyroid hormone preconditioning: protection against ischemia-reperfusion liver injury in the rat," Hepatology, vol. 45, no. 1, pp. 170-177, 2007.

[24] C. Ferreyra, F. O’Valle, J. M. Osorio et al., "Effect of preconditioning with triiodothyronine on renal ischemia/reperfusion injury and poly(ADP-ribose) polymerase expression in rats," Transplantation Proceedings, vol. 41, no. 6, pp. 2073-2075, 2009.

[25] E. Erkan, A. Sakarcan, G. Haklar, and S. Yalcin, "Thyroxine prevents reoxygenation injury in isolated proximal tubule cells," Pediatric Nephrology, vol. 18, no. 7, pp. 636-643, 2003.

[26] P. M. Sutter, G. Thulin, M. Stromski et al., "Beneficial effect of thyroxin in the treatment of ischemic acute renal failure," Pediatric Nephrology, vol. 2, no. 1, pp. 1-7, 1988.

[27] C. Verga Falzacappa, C. Mangialardo, L. Madaro et al., "Thyroid hormone T3 counteracts STZ induced diabetes in mouse," PLoS One, vol. 6, no. 5, Article ID e19839, 2011.

[28] C. Verga Falzacappa, E. Timperi, B. Bucci et al., " $\mathrm{T}_{3}$ preserves ovarian granulosa cells from chemotherapy induced apoptosis," Journal of Endocrinology, vol. 215, pp. 281-289, 2012.

[29] M. Bhargava, M. R. Runyon, D. Smirnov et al., "Triiodo-Lthyronine rapidly stimulates alveolar fluid clearance in normal and hyperoxia-injured lungs," American Journal of Respiratory and Critical Care Medicine, vol. 178, no. 5, pp. 506-512, 2008.

[30] C. I. Pantos, V. A. Malliopoulou, I. S. Mourouzis et al., "Longterm thyroxine administration protects the heart in a pattern similar to ischemic preconditioning," Thyroid, vol. 12, no. 4, pp. 325-329, 2002. 
[31] J. A. Kuzman, A. M. Gerdes, S. Kobayashi, and Q. Liang, "Thyroid hormone activates Akt and prevents serum starvationinduced cell death in neonatal rat cardiomyocytes," Journal of Molecular and Cellular Cardiology, vol. 39, no. 5, pp. 841-844, 2005.

[32] Y. F. Chen, S. Kobayashi, J. Chen et al., "Short term triiodo1-thyronine treatment inhibits cardiac myocyte apoptosis in border area after myocardial infarction in rats," Journal of Molecular and Cellular Cardiology, vol. 44, no. 1, pp. 180-187, 2008.

[33] M. Dentice, A. Marsili, R. Ambrosio et al., "The FoxO ${ }_{3}$ /type 2 deiodinase pathway is required for normal mouse myogenesis and muscle regeneration," The Journal of Clinical Investigation, vol. 120, no. 11, pp. 4021-4030, 2010.

[34] A. Marsili, D. Tang, J. W. Harney et al., "Type II iodothyronine deiodinase provides intracellular 3,5, $3^{\prime}$-triiodothyronine to normal and regenerating mouse skeletal muscle," American Journal of Physiology, vol. 301, no. 5, pp. 818-824, 2011.

[35] K. Fukuyama, T. Ichiki, I. Imayama et al., “Thyroid hormone inhibits vascular remodeling through suppression of cAMP response element binding protein activity," Arteriosclerosis, Thrombosis, and Vascular Biology, vol. 26, no. 9, pp. 2049-2055, 2006.

[36] J. D. Safer, T. M. Crawford, and M. F. Holick, "A role for thyroid hormone in wound healing through keratin gene expression," Endocrinology, vol. 145, no. 5, pp. 2357-2361, 2004.

[37] R. Kassem, Z. Liberty, M. Babaev et al., "Harnessing the skinthyroid connection for wound healing: a prospective controlled trial in guinea pigs," Journal of Clinical \& Experimental Dermatology, vol. 37, no. 8, pp. 850-856, 2012.

[38] E. Kress, A. Rezza, J. Nadjar, J. Samarut, and M. Plateroti, "The thyroid hormone receptor- $\alpha(\mathrm{TR} \alpha)$ gene encoding TR $\alpha 1$ controls deoxyribonucleic acid damage-induced tissue repair," Molecular Endocrinology, vol. 22, no. 1, pp. 47-55, 2008.

[39] J. Horacek, S. Dusilova Sulkova, M. Kubisova et al., "Thyroid hormone abnormalities in haemodialyzed patients: low triiodothyronine as well as high reverse triiodothyronine are associated with increased mortality," Physiological Research, vol. 61, no. 5, pp. 495-501, 2012.

[40] C. V. Falzacappa, C. Mangialardo, S. Raffa et al., “The thyroid hormone T3 improves function and survival of rat pancreatic islets during in vitro culture," Islets, vol. 2, no. 2, pp. 96-103, 2010.

[41] H. G. Folkesson, A. Norlin, Y. Wang, P. Abedinpour, and M. A. Matthay, "Dexamethasone and thyroid hormone pretreatment upregulate alveolar epithelial fluid clearance in adult rats," Journal of Applied Physiology, vol. 88, no. 2, pp. 416-424, 2000. 


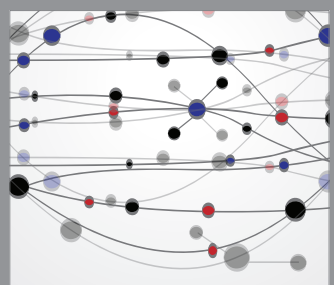

The Scientific World Journal
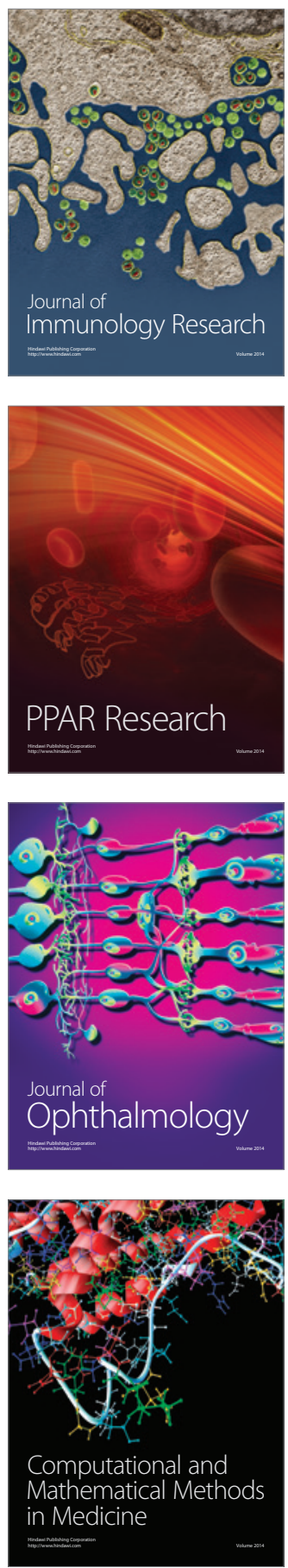

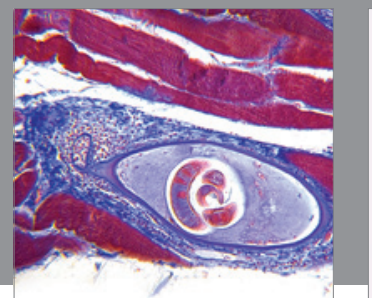

Gastroenterology

Research and Practice
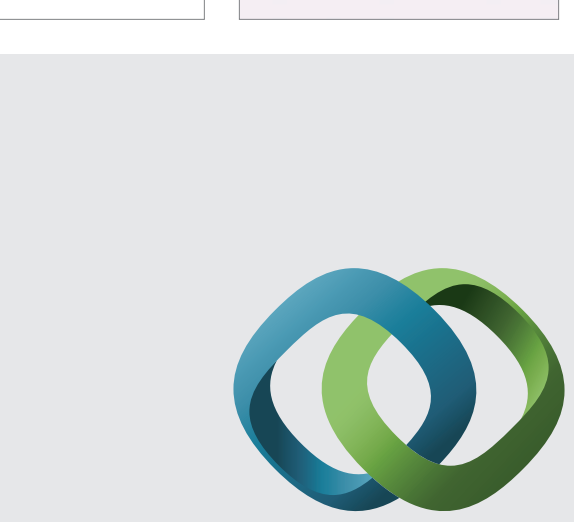

\section{Hindawi}

Submit your manuscripts at

http://www.hindawi.com
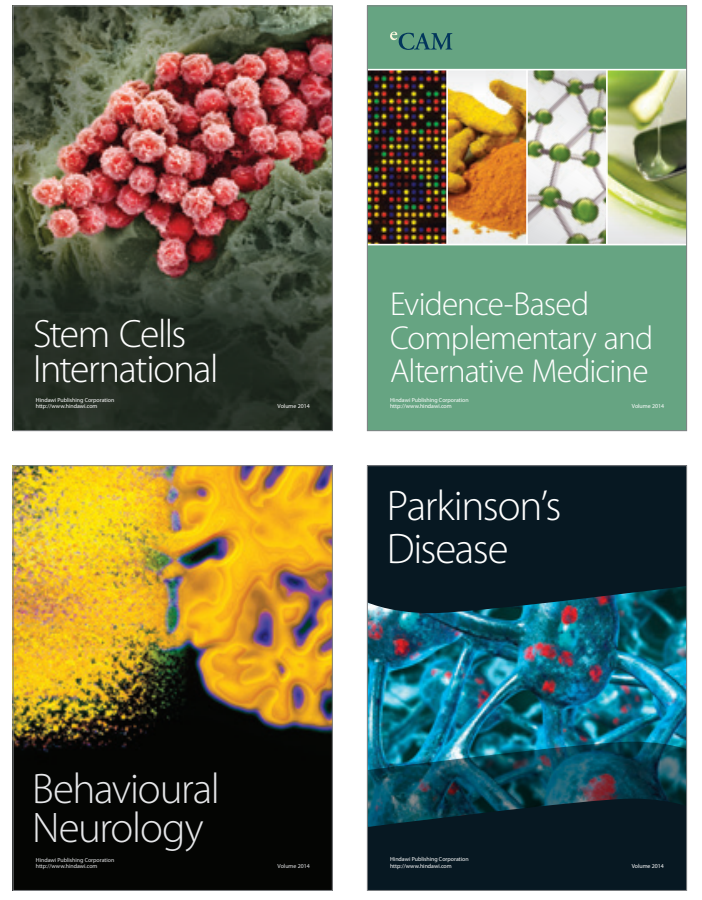
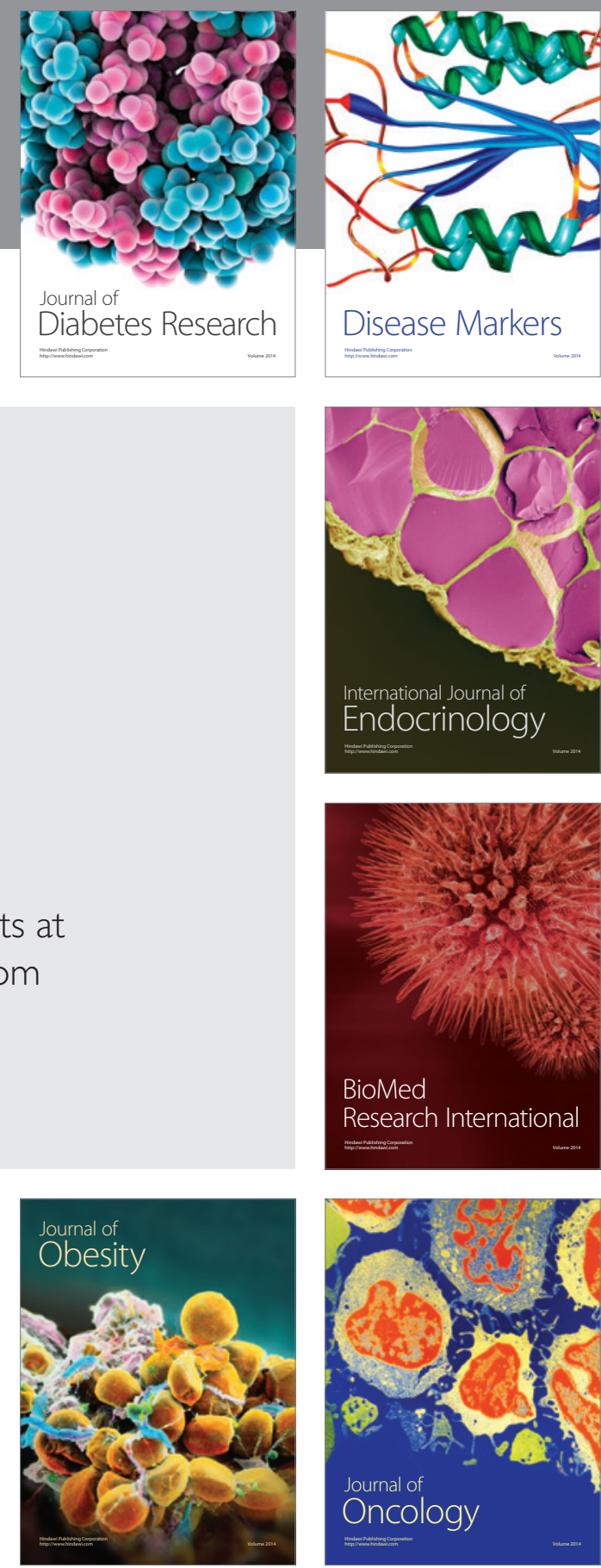

Disease Markers
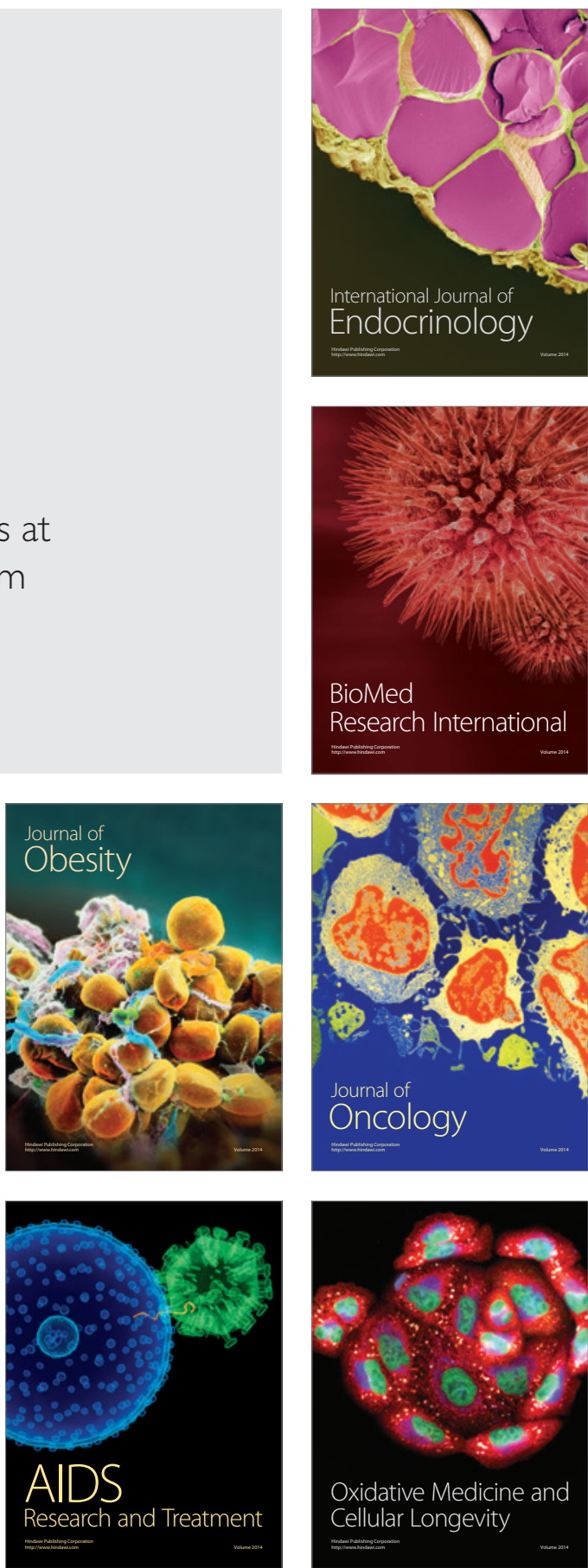